\title{
Obituary.
}

Srr EDWART) MALINS, M.Sc. (Birm.), M.D.(Edin.). F.R.C.P. (Lond.).

WE regret to have to record the death, on July 23 rd, of Sir Edward Malins, one of the founders and original directors of this Journal. Sir Edward was in his 8rst year, and continued to practise until two or three months before his death.

The youngest son of Dr. Samuel Malins, one of the founders of the Liverpool School of Medicine, Malins was educated at King Edward's School, Birmingham, and afterwards articled to Dr. Thomas Underhill, of Great Bridge. He then went to Edinburgh and took the degree of M.B., C.M., in I866, the M.D. degree following in 1869. In the latter year he commenced general practice at Cradley Heath with marked and rapid success. Three years later, in $187^{2}$, he removed to Birmingham, where he spent the remainder of his life. Ile was early appointed Medical Officer of the old Birmingham Lying-in Charity and the Women's Hospital, and in 1876 was elected Obstetric Physician to the General Hospital when the special department was first opened. This appointment he held for 25 years, when he became Consulting Obstetric Physician. In November I894, when the old medical school of Queen's College was transferred to Mason Coilege, which was ultimately merged in the University, he was appointed Professor of Obstetrics, and this position he held for 18 years. On his resignation in IgI 2 the Court of Governors conferred upon him the title of Emeritus Professor.

Shortly after coming to Birmingham Sir Edward-became a Member of the Royal College of Physicians, and in 1902 was elected a Fellow. In I90I the Birmingham University conferred upon him the degrce of M.Sc., and in the same year he was elected President of the Birmingham Branch of the British Medical Association, choosing for his address the subject of Midwifery and Midwives in its historical aspect. He was President of the Midland Medical Society in 1882, and in 1903-4 and 1904-5 he became President of the Obstetrical Society of London. Sir Edward was also President of the Section of Midwifery and Gynzcology at the meetings of the British Medical Association at Bristol, Ryde and Birmingham. 


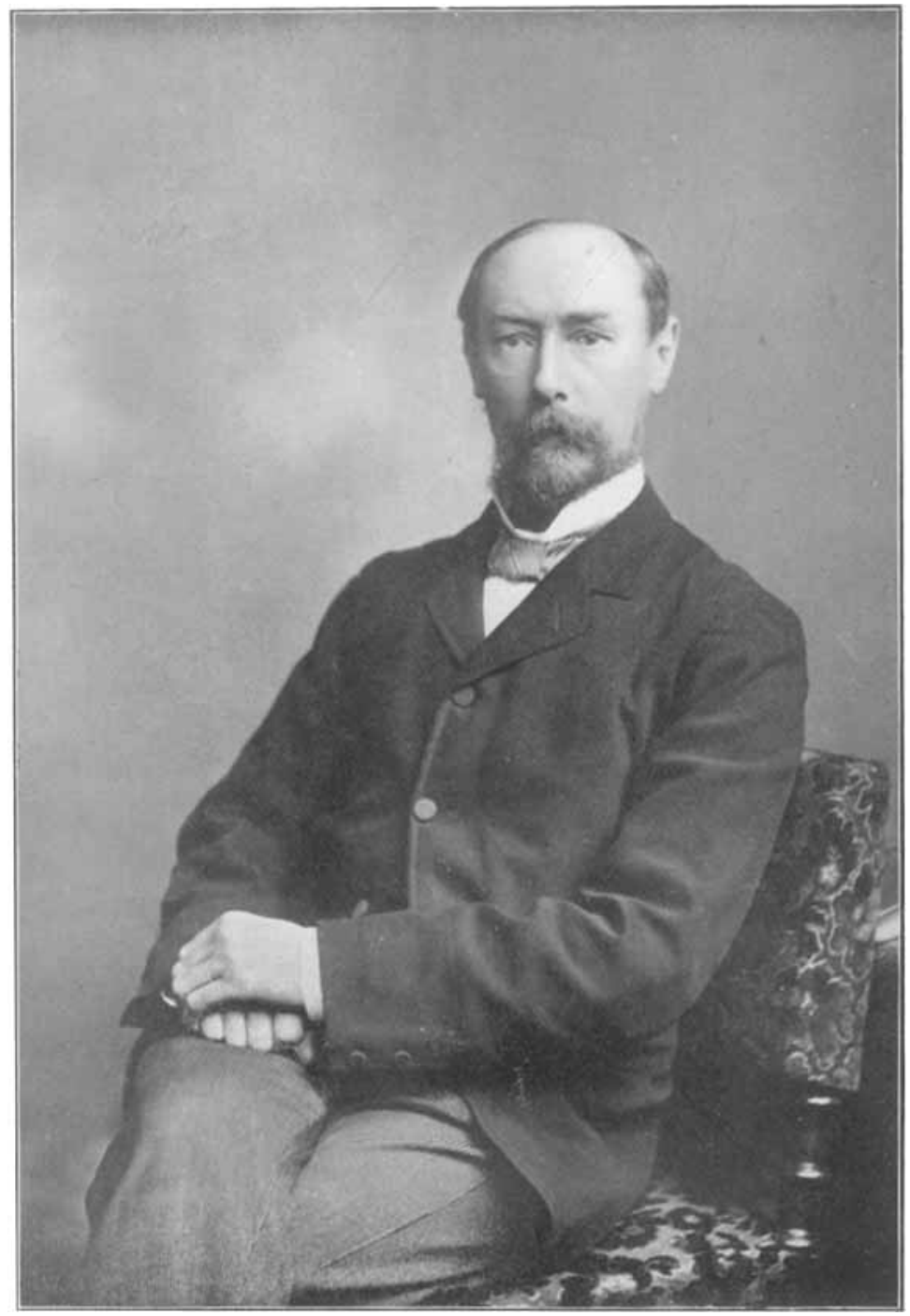

'THE LA'TE SIR EDWARD MAI.INS. 
At various times he officiated as examiner in his subject for the Conjoint Board, for the Lniversity of Bristol, the Victoria University of Manchester, and the Central Midwives' Board. He made many valuable contributions to medical literature, and wrote the section on Uterine Inversion in "Allbutt and Playfair's System of Gynacology." For his essay on the Pathology and Treatment of Diseases of the Ovaries in 1873 he was awarded the Hastings Medal of the British Medical Association.

Thirty years ago, when I became his junior colleague at the old General Hospital, Malins had already been in practice in Birmingham for 20 years, and his name was a household word in the city and a large surrounding district. I was at once impressed by the constant and punctual discharge of his hospital duties and by his devotion to any sympathetic interest in his patients, as well as by his knowledge and skill. His patients looked up to him with esteem and respect, and returned his care with real affection. In the students he took a close and kindly interest, and to his colleagues, and especially the juniors, he was ever considerate and loyal. When illness or misfortune overtook those who had worked with him his ready sympathy, and, when needed, his generous help were unobtrusively given. Malins became a specialist by virtue of a long and arduous training, first by apprenticeship, then by the usual course in the University of Edinburgh, and afterwards by some years in busy general practice. Before leaving Edinburgh he had become assistant to Sir James Simpson, and had been Iouse Surgeon to the Royal Maternity Hospital, and so had acquired a sound practical acquaintance with the principles of midwifery and diseases of women. Through the whole of his life his mind remained open to new ideas, and he earnestly and successfully strove to keep abreast of advances in knowledge and practice, as the speciality developed from the era of mechanical pathology and pessaries to that of more modern surgical and scientific methods.

As professor in the University, Malins took the greatest pains to keep his teaching on the highest and most advanced level, was assiduous and punctual in the discharge of his duties, and possessed the esteem and regard of the students to a marked degree. As an examiner he was impartial, patient and considerate. A large part of his life was devoted to the services of the General Hospital and of the University, in both of which he took a profound interest, giving to them of his best. Outside his professional work he had many interests. A devoted and hard-working churchman, he practised his religion without ostentation in his daily life. In political and social matters he took an active nterest, and of general literature he was a diligent and widely read student. At the University Graduates' Club, of which he was twice president, he 
was a regular attendant and was one of the most valued and interesting speakers. In daily intercourse Malins bore himself with quict and unassumnig courtesy. To him came many honours, unsought, modestly accepted, and sustained with dignity. Among them, the most welcome to his local brethren, and, I think, to himself, was the highest in the power of the members of his speciality to bestow, the Presidency of the London Obstetrical Society, to which office he was the first provincial member to be elected. His presence and example will be missed in many circles, and his place will not readily be filled.

Sir Edward Malins, who was knighted in I919, and was a J.P. for the county of Warwick and for the city of Birmingham, married, in 1869, Mary, daughter of Edward Owen, C.E., by whom he had five sons and one daughter. His eldest son, Dr. Herbert Malins, is in practice at Warwick, and was recently Mayor of the town.

T. W.

\section{GORDON LEY.}

GoRdon LEY was killed in an aeroplane accident on June $3^{\text {rd. }}$ Only 36 years of age at the time of his death, he had concentrated into his short career a volume of work such as men, many years his senior, might well feel content to have achieved.

He was educated at Malvern and the London Hospital, qualifying in 1908, and becoming F.R.C.S. (Eng.) in 1912 , and M.R.C.P. in 1913. He had a brilliant career as a student and showed an early interest in Obstetrics anl Gynacology by winning the Prize awarded in these subjects. After acting as Pathological Assistant at the London Hospital, he went as House Surgeon to the Royal Gloucester Infirmary in I9Io; from there he was appointed to the posts of junior and senior resident Medical Officer to Queen Charlotte's Hospital. It was this appointment which determined his choice of a career; he took up the study of Obstetrics with enthusiasm, and his great natural ability and untiring energy soon became apparent. In 1913, he was appointed Pathologist to the Chelsea Hospital for Women; in 19I4, Obstetrical Registrar and Tutor to Charing Cross Hospital, which appointment he held almost up to the time of his death; in the same year, Pathologist and Registrar and, in 1919, Assistant Obstetric Surgeon to the City of London Maternity Hospital; and in 1918, Gyndecologist to the Hampstead Hospital. Both the latter appointments he held up to the time of his death.

Unable, for reasons of health, to join the Medical Service of 
the Army, he volunteered at the outbreak of war to act as Resident Medical Officer to the City of London Maternity Hospital, and remained in that capacity until after the Armistice; the amount of work that this entailed may be realized from the fact that during the latter part of the war all the members of the Medical Staff (with the exception of the Senior Surgeon, who was away from London on military duty for one half of every week) were on Active Service with the army abroad. Gordon Ley, therefore, acted in the capacities of the Medical Staff, the Pathologist and the Resident Medical Officer combined. This, in itself, was enough to occupy the whole time and energy of any ordinary man. But it was not by any means enough for Ley; for, besides carrying on his duties at Charing Cross and Hampstead General Hospitals and the Chelsea Hospital for Women, he, in addition to this amazing list of duties, acted as Obstetric Registrar and Tutor, and, from 1917 onwards, as Acting Assistant Obstetric Surgeon to the London Hospital; even this did not satisfy this insatiate man, for during the same period he became Consulting Obstetrician and Lecturer to the Jewish Maternity Home, Underwood Street, took his turn of duty at Lady Howard de Walden's Maternity Home for the Wives of Officers, and lectured all the years of the war twice a week at the Midwives' Institute. How he survived the strain of all this work was a continual source of wonder to everyone who knew him; for he was a man of frail physique, with congenital valvular disease of the heart and glycosuria, and was rejected as totally unfit for military service. Whilst he was living in at the City of London Maternity Hospital he was seldom in bed before 2 or 3 a.m., and vet by 9 a.m. he had done his complete round of the wards, had written his incomparable case-notes, and had departed to perform his multifarious duties elsewhere.

During all this time, what is perhaps most of all to be wondered at, he found time for original research, and has left us with a short series of papers of outstanding merit on clinical and pathological subjects connected with Obstetrics and Gynacology. Nearly all his work was published either in this Jovnsal or in the Proceedings of the Royal Society of Medicine. His earlier papers were chiefly on pathological subjects, and included accounts of "Lipomatosis of a Fibromyoma of the Uterus" and "Decidual Reaction in a Subperitoncal Fibromyoma of the Uterus." In I9r9 he published two big papers on "Two Cases (personal) of Extrauterine Pregnancy at Term, with a tabulated abstract of roo cases from the literature," and "Primary and Secondary Carcinoma of the Ovary." In I920 and 1921, he did his most important work, that on accidental hæmorrhage, which he published in two papers, "Utero-placental (Accidental) Hamorrhage; clinical report of 
50 consecutive cases," and "Pathology of Utero-placental (Accidental) Hamorthage." On the clinical side he produced convincing evidence for regarding this complication as toxæmic in origin, and on the pathological side, from the results of microscopic examination of uteri removed for this condition, he was able to offer an explanation for the bleeding by the demonstration of focal necrosis in the uterine wall. This paper will become of historic importance, and the starting point for future work on the same subject.

Ley was to have opened the discussion on Primary Carcinoma of the Ovary at the Annual Meeting in August of the British Medical Association at Glasgow. He also contributed short papers to various medical journals, and several articles to systems of Obstetrics. He was a member of the Council of the Obstetrical and Gynzecologrical Section of the Royal Society of Medicine, and was a member of the Special Committee appointed to investigate the action of "twilight sleep," and was also sectetary of the Special Committee on the teaching of Obstetrics and Gynacology.

As may be gathered from the foregoing, Gordon Ley was a remarkable man with an outstanding-even a peculiar-personality. Fis mental ability was undoubted; he had a quick, perceptive intelligence, and a remarkably retentive memory; anything he took up he pursued with a restless, enthusiasm; the continuity of his energy was remarkable. He has been described as one of the ablest men of his standing in the whole country. Had he lived, there is no doubt he would have done work of even historic importance. Integrity itself in his own work, he was intolerant and impatient of anything that he thought was slackness or sham in that of others. Like all men of his mental calibre, he did not suffer fools gladly; quick of speech as of thought, outspoken, with a self-confidence almost reckless, with an independence of thought that amounted to persistent iconoclasm, it was no wonder that all men were not his friends. But his many friends and admirers knew him to be intensely sensitive, generous and warmhearted. Gordon Ley will always be remembered as he would have wished, for his work, and for his career of ceaseless activity and high ideals in the pursuit of knowledge.

E. $\mathrm{H}$. 